\title{
Experimental Study on Dynamic Mechanical Property of Cemented Tailings Backfill by SHPB
}

\author{
Yu-ye TAN ${ }^{1,2)}{ }^{*}, X_{\text {in }} Y U^{1,2)}$, Lin-hui XU ${ }^{1,2)}$, Wei-dong Song ${ }^{1,2)}$ \\ 1 Key Laboratory of High-Efficient Mining and Safety of Metal Mines (Ministry of Education of China), University \\ of Science and Technology Beijing, Beijing 100083, China \\ 2 School of Civil and Resources Engineering, University of Science and Technology Beijing, Beijing 100083, China \\ * Correspondence, tanyuye@ ustb.edu.cn; Tel.: +86 15910707786
}

\begin{abstract}
In recent years, cemented tailings/paste backfill (CPB) become more and more important to maintain mine structure and keep mining stope to be stable in deep underground mining. Deep mining process often accompanied by blasting, rock burst and other high-speed dynamic loading. So it's important to make research on dynamic behavior and characteristics of CPB. In this paper, a series of dynamic loading tests on CPB specimens by SHPB were taken to study the characteristic of stressstrain, dynamic strength, deformation and failure of $\mathrm{CPB}$. The experimental results revealed that some CPB specimens have 1 2 lower stress peaks after reaching the peak stress before getting completely failed. The greater the cement-sand ratio was, the more obvious of strain reaction was. This property mainly showed like follows. The greater the cement-sand ratio was, the greater the dynamic compressive strength was under similar velocity impact; the dynamic compressive strength and the average strain rate were quadratic equation relationship, and the greater the cement-sand ratio was, the higher increase rate of dynamic compressive strength caused by strain rate. The dynamic compressive strength enhancement factor increased with the increase of the strain rate, and is larger than that of rock samples. The failure forms of CPB specimens under low-speed impact were almost the same as them under static uniaxial and triaxle compression. The CPB specimens were crushed broken under the critical strain rate, similar to the failure mode of low strength concrete. The experimental research results will improve our understanding the dynamic mechanical property of CPB and help to guide the strength design of deep mining backfill.
\end{abstract}

Key words: dynamic loading test; $\mathrm{CPB}$ (cemented tailings/paste backfill); mechanics characteristic; SHPB (Split Hopkinson Pressure Bar)

\section{Introduction}

With the decreasing of surface and shallow's resources, mining industry has gradually developed to deep level ${ }^{[1]}$. That causes lots of problems, such as complex stope underground pressure appearance, frequently rock burst, high working temperature, increasing ascension difficulty, high mining cost and so on ${ }^{[2-4]}$. Meanwhile, massive solid waste generated from mineral and mining processing and been deposited to tailings dam or waste dump, which have a negative effect on the surface ground water and the ecological environment, and will result in geological (e.g., tailings dam failures) and environmental (e.g., acid mine drainage, heavy metal leaching and groundwater pollution) hazards ${ }^{[5-}$ 8].

Recent years, a new developed cemented backfilling technology (CBT), known as cemented tailings/paste backfilling (CPB) is widely used in deep mining to solve the above problems. CPB is a kind of relatively new green material that artificially engineered mixture of tailings, binder, and water 
[9-12]. Filling the mined-out area with CPB can do much help to control the strata movement and surface subsidence, reduce emissions of waste rock and tailings to land, reduce ore dilution of mining cycles, and improve the working environment ${ }^{[13-18]}$. The CBT method has more advantages than the conventional slurry backfill method (e.g., rock fill and hydraulic fill). It is especially important in providing a safe work environment for mining activities, allowing ground support and a better means of tailings disposal.

The mechanical property is the key factor to ensure the stability of openings, as well as the safety of operators and equipment in the adjacent stope ${ }^{[19]}$. Many scholars have achieved a lot by a large number of experimental studies on the static mechanical properties of CPB ${ }^{[20-26]}$. Xu Wen-bin et al. figured out the internal relationship between the deformation characteristics, failure modes, energy dissipation of CPB at different loading stages and confining pressure ${ }^{[27-28]}$. Studies made by Yilmaz assessed the effect of curing stress conditions on the mechanical strength and microstructural properties of cemented paste backfills ${ }^{[29-31]}$. Dong $\mathrm{Lu}$ et al. obtained cementitious diagenesis microcosmic rules and hydration mechanism of ultra-fine tailing materials under different conditions by XRD (X-Ray Diffraction) energy spectrum analysis and SEM (Scanning Electron Microscopy) ${ }^{[32]}$. Previous studies revealed that three main backfill components (tailings, binder, and particle size distribution) can affect the mechanical and durability properties of CPB.

There is not only static mechanical action but also a lot of high velocity dynamic impact existed in mining process (e.g., explosion and rock burst). These often cause fracture propagation and damage to backfill body, or even collapsing in stope. For this reason, some scholars did some exploratory research on the stability and mechanical property $\mathrm{C} \mathrm{CPB}$ under dynamic loading conditions. Liu Zhixiang et al. conducted both dynamic and static strength test of $\mathrm{CPB}$, found that the strength of $\mathrm{CPB}$ increases with the loading rate only at a low strain rate ${ }^{[33]}$. Li Na analyzed the influence of mediumlength blasting's dynamic loading on CPB's stability by LS-DYNA [34]. Zhang Qin-li did an experiment of HTB (High Density Tailing Backfill) by impacting samples by different speeds with SHPB (Split Hopkinson Pressure Bar), and concluded HTB is more likely to instability with the raising of strain rate ${ }^{[35]}$. It is generally discovered and acknowledged that the compressive strength of CPB under dynamic load is significantly higher than that under static load ${ }^{[36]}$.

However, in addition to the three main backfill components (tailings, binder, and particle size distribution), there are so many other factors would affect the compressive strength and mechanical property of CPB under dynamic load (e.g., laboratory equipment, strain rate, internal structure, aggregate composition, etc.). It's necessary to do study to find the sensitivity factors of strength increasing and identify the mechanical behavior characteristics of CPB under dynamic loading. The article took an experimental study on the dynamic mechanical property of CPB specimens by SHPB, try to find the variation relationship of stress and strain, the value variation of the dynamic peak strength, the deformation and failure type and characteristics of CPB under dynamic loading. The research results are extremely important to get an in-depth understanding of the mechanical properties of CPB. It will make important engineering significance on studying CPB.

\section{Materials and Methods}

\subsection{Split Hopkinson Pressure Bar (SHPB)}

Split Hopkinson Pressure Bar (SHPB, as shown in Fig.1) is an efficient equipment for testing mechanical response of composite materials like rock, concrete et al. at high stress rate ${ }^{[37]}$. When take the test, the bullet punch hits against the incident bar (input Bar) at a certain speed and produce stress 
wave. The stress wave spread along the incident bar to the interface between specimen and the elastic rod. Part of the stress wave reflects to the incident bar, rest of them penetrates into the transmission bar (Output Bar), and income to the absorbing bar.

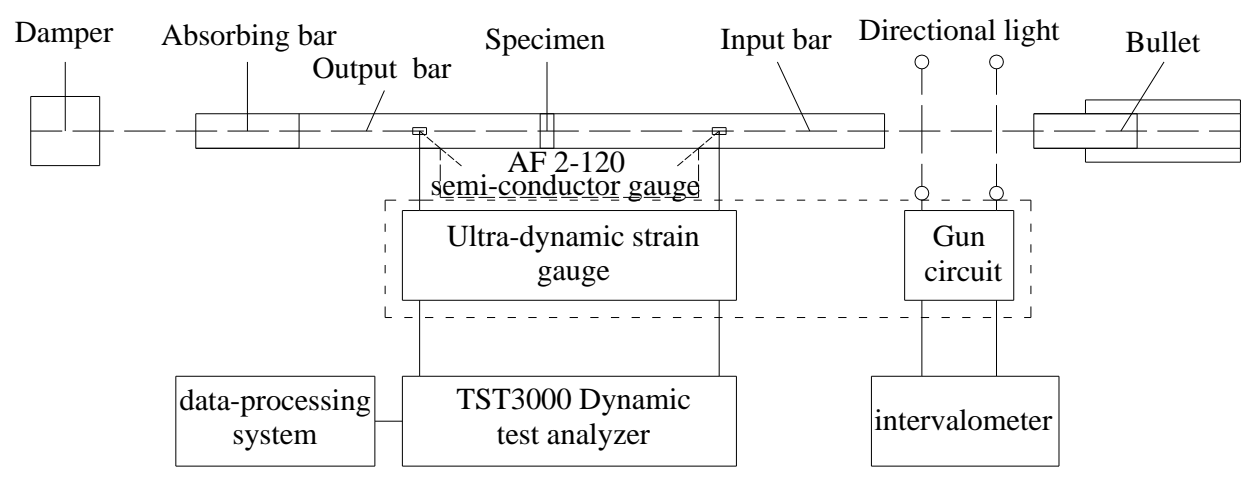

Fig 1. Split Hopkinson Pressure Bar testing system

Assuming that the incident wave propagates in the incident bar with a wave velocity of $C_{0}$, then the calculation equations of strain rate $\frac{d \varepsilon_{S}}{d t}$, strain $\varepsilon_{S}$ and stress $\sigma_{S}$ can be worked out by following formulas ${ }^{[38]}$ :

$$
\begin{aligned}
& \frac{d \varepsilon_{s}}{d t}=\frac{C_{0}}{l_{0}}\left(\varepsilon_{i}-\varepsilon_{r}-\varepsilon_{t}\right) \\
& \sigma_{s}=\frac{E A}{2 A_{0}}\left(\varepsilon_{i}+\varepsilon_{r}+\varepsilon_{t}\right) \\
& \varepsilon_{S}=\frac{C_{0}}{l_{0}} \int_{0}^{t}\left(\varepsilon_{i}-\varepsilon_{r}-\varepsilon_{t}\right) d_{t}
\end{aligned}
$$

Where $E$ is the elastic modulus of the press bar, $\mathrm{MPa} ; A$ and $A_{0}$ are the cross-sectional area of press bar and sample respectively, $\mathrm{m}^{2} ; l_{0}$ is the height of sample, mm; $\varepsilon_{i}, \varepsilon_{r}$ and $\varepsilon_{t}$ are the signals of input, reflect and transmission respectively.

\subsection{Size of the CPB Specimens and Preparation}

Similar to concrete specimen, $\mathrm{CPB}$ is a kind of elastic brittleness material. The existing experimental research results of concrete specimens with different diameters and slenderness ratios show that the strength of specimens decreases with the increase of size. According to the ISRM (International Society of Rock Mechanics and Rock Engineering) and Chinese test procedures, it is recommending that the diameter should not be less than $50 \mathrm{~mm}$ when use cylindrical rock sample ${ }^{[38]}$. Besides, $\mathrm{Xu}$ Jin-yu et al. proposed that the proper slenderness ratio of cylindrical samples should between 0.4 and $0.6^{[39]}$. In this experimental, considering the applicability of the SHPB device, CPB specimens were designed to be cylindrical shape with $50 \mathrm{~mm}$ diameter and $0.5 \sim 0.6$ slenderness ratio. A SHPB system device with $\varphi 50 \mathrm{~mm}$ vacuum rod was used to do the test.

Slurry mixed by classified tailings from a gold mine, $425 \#$ portland-cement and water were used to make the CPB specimens, with cement-sand ratio of $1: 4,1: 6,1: 8$ and concentration of $70 \%$ and $75 \%$. 30 CPB specimens were made (6 groups of different cement-sand ratio and concentration, 5 specimens in each group). After curing 90 days in a standard curing box, the $30 \mathrm{CPB}$ specimens looks like shown in Fig 2. 

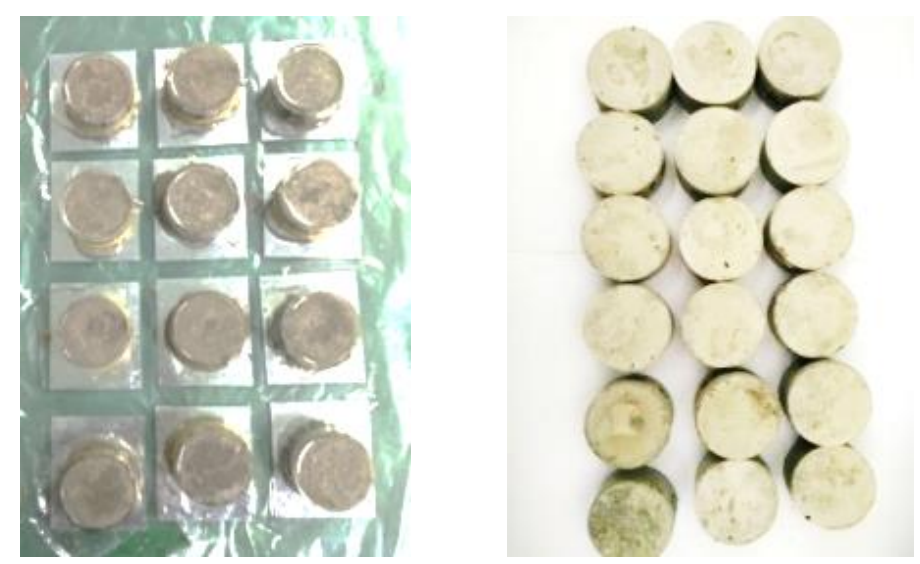

Fig 2. CPB specimens made by slurry mixed by classified tailings, $425 \#$ portland-cement and water with cementsand ratio of 1:4, 1:6, 1:8 and concentration of 70\% and 75\%. They were classified into 6 groups by cement-sand ratio and concentration (Group 70-4-90, Group 75-4-90, Group 70-6-90, Group 75-6-90, Group 70-8-90, Group 75-8-90). Group number represents the corresponding parameters of CPB specimens. For example, Group 70-490 means the slurry concentration is $70 \%$, the cement-sand ratio is $1: 4$ and the maintenance time is $90 \mathrm{~d}$. while in below, 70-4-90-1 represents the No. 1 specimen of the Group 70-4-90.

\subsection{Physical Parameters of the CPB Specimens}

The physical properties of all CPB specimens were measured. The average values of each group's physical parameters are shown in Table 1. Obviously, the quality parameters (quality, density) of each groups verified with the cement-sand ratio and concentration, while the dimension parameters (height, volume, sectional area and slenderness ratio) of them almost the same.

Table 1. Physical parameters of the CPB specimens $(\varphi=50 \mathrm{~mm})$

\begin{tabular}{lcccccc}
\hline Group Number & $\begin{array}{c}\text { Quality } \\
/ \mathbf{g}\end{array}$ & $\begin{array}{c}\text { Density } \\
/ \mathbf{g} \cdot \mathbf{c m}^{\mathbf{3}}\end{array}$ & $\begin{array}{c}\text { Height } \\
\mathbf{/ m m}\end{array}$ & $\begin{array}{c}\text { Volume } \\
/ \mathbf{c m}^{\mathbf{3}}\end{array}$ & $\begin{array}{c}\text { Sectional Area } \\
/ \mathbf{c m}^{\mathbf{2}}\end{array}$ & Slenderness Ratio \\
\hline Group 70-4-90 & 107.02 & 1908.43 & 28.56 & 56.08 & 19.63 & 0.57 \\
Group 75-4-90 & 102.50 & 1786.55 & 29.23 & 57.38 & 19.64 & 0.59 \\
Group 70-6-90 & 107.02 & 1908.43 & 28.56 & 56.08 & 19.63 & 0.57 \\
Group 75-6-90 & 99.17 & 1757.98 & 28.73 & 56.41 & 19.63 & 0.58 \\
Group 70-8-90 & 107.02 & 1908.43 & 28.56 & 56.08 & 19.63 & 0.57 \\
Group 75-8-90 & 96.83 & 1698.58 & 29.04 & 57.01 & 19.63 & 0.58 \\
\hline
\end{tabular}

\section{Results and Discussion}

\subsection{Dynamic Mechanical Test}

Frist, uniaxial impact tests by SHPB were taken to the Group 70-4-9 CPB specimens, to get the impact waveform diagram of each CPB specimens, as shown in Fig 3.

Obviously, voltage peaks of the incident wave and transmission wave increased with the increase of impact rate. Moreover, the amplitudes of incident and reflected waves were the same, but greater than that of reflected wave. This phenomenon can be explained by the wave impedance theory ${ }^{[40]}$ : the wave impedance ratio of the incident bar and CPB specimens is large. This results in the stress amplitude of the transmission wave being much smaller than that of the incident wave. It's also a good 
sign that $\mathrm{CPB}$ specimen has strong damping and shielding effect on elastic wave propagation, which is beneficial to the overall stability of CPB body in the underground mining stope.

According to the previous experiments and research result, impact velocities between $2.5 \sim 7.5 \mathrm{~m} \cdot \mathrm{s}^{-1}$ were used to take uniaxial impact tests by SHPB. Corresponding signal values and failure forms were recorded, and strain rate and stress peak were calculated out according to the above formulas (1), (2) and (3).
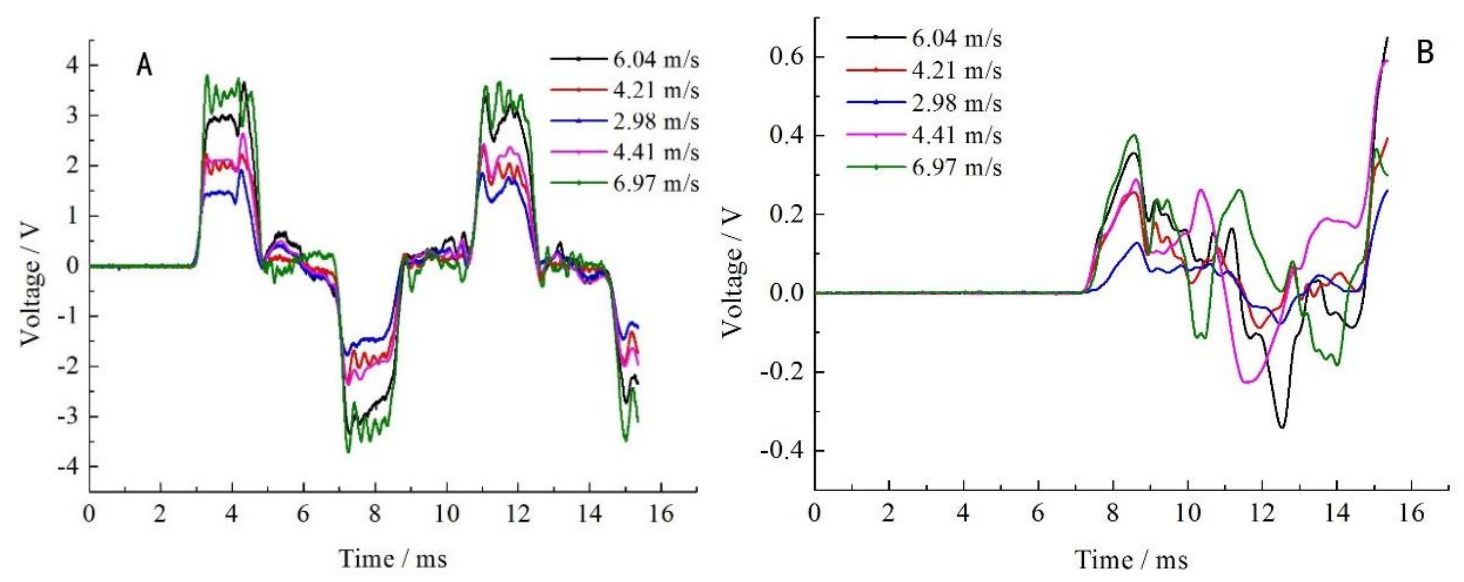

Fig 3. SHPB impact waveform of CPB specimens of Group 70-4-9. (A) Incident and reflected wave curves; (B) Transmission wave curves. The voltage peak of incident wave and transmission wave increases with the increase of impact rate; But the stress amplitude of the transmission wave were much smaller than that of the incident wave.

\subsection{Characteristics and Relationship of Stress and Strain}

According to the SHPB uniaxial compression test results, stress-strain curves of different Groups were obtained, as shown in Fig 4. (A-F).

(1) When the concentration and cement-sand ratio are constant, the dynamic peak stress of CPB specimens increased with the increase of impact velocity.

(2) The dynamic peak stress of CPB specimens had a significant influence on CPB's cementsand ratio. Under similar impact velocity, the larger cement-sand ratio was, the greater peak stress was.

(3) When the concentration and cement-sand ratio are constant, the strain presented increasing tendency with the increase of impact velocity at the dynamic peak stress. However, the strain value under SHPB uniaxial impact was far less than the maximum strain of specimen under static compression, which had the same concentration and cement-sand ratio. 

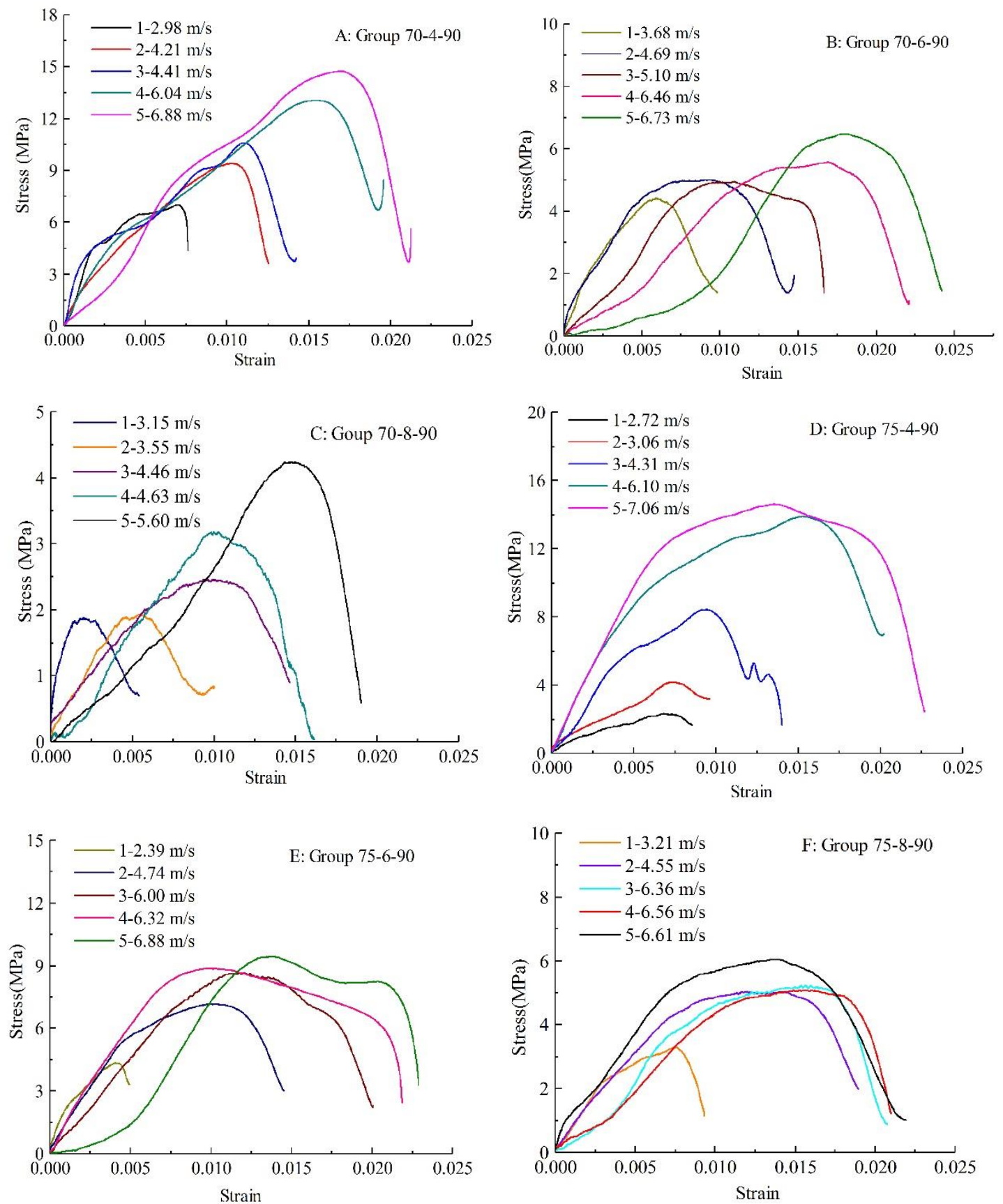

Fig 4. Stress-strain curves of CPB specimens under SHPB uniaxial compression test. Curve (A) Group 70-4-90; Curve (B) Group 70-6-90; Curve (C) Group 70-6-90; Curve (D) Group 75-4-90; Curve (E) Group 75-6-90; Curve (F) Group 75-8-90. The dynamic peak stress of backfill specimen increased with the increase of impact velocity. Under similar impact velocity, the larger cement-sand ratio was, the greater peak stress was. Besides, the strain value under SHPB uniaxial impact was far less than the maximum strain of specimen under static compression.

According to the results under SHPB uniaxial compression test, the deformation and failure process of CPB specimens can be divided into following four stages, as shown in Fig 5. (A):

Micro-crack closure stage (OA): the curve shows a concave shape, indicating that internal crack gradually closed under compressive pressure, the specimen generated nonlinear deformation. However, some CPB specimens' Micro-crack closure stage was not obvious or hard to discover, as shown in Fig 5. (B), the OA section of CPB specimen NO.75-4-90-5 almost disappeared. 
Elastic deformation stage $(\mathrm{AB})$ : at this stage, stress concentration occurred around the inner primordial pore, but the value of it was still not large enough to make the internal micro-cracks extending and bursting. In accordance with Hooke's law, the curve was approximately as a straight proportional line. The slope of the line that connecting $\mathrm{AB}$ section approximately regarded as the elastic modulus of the $\mathrm{CPB}$ specimen under certain concentration, cement-sand ratio and strain rate.

Inelastic stage $(\mathrm{BC})$ : the curve began to convex, that meant the $\mathrm{CPB}$ specimen began to have inelastic deformation. The stress value around the micro-crack exceeded the limit and resulted in innercrack expanding and rupturing. The original previous damage gradually propagated and become worse till the stress reach to the peak value (dynamic peak stress) at point $\mathrm{C}$.

Crack penetration and failure stage $(\mathrm{CD})$ : the micro-cracks continued to expand and bifurcate with winding and communication, etc. After that, the deformation of CPB specimens began to a weakening stage after the dynamic peak stress. The leading cracks were gradually formed, with a direction nearly parallel to the principal stress direction, and the CPB specimen cracked along the leading crack until it was damaged overall.
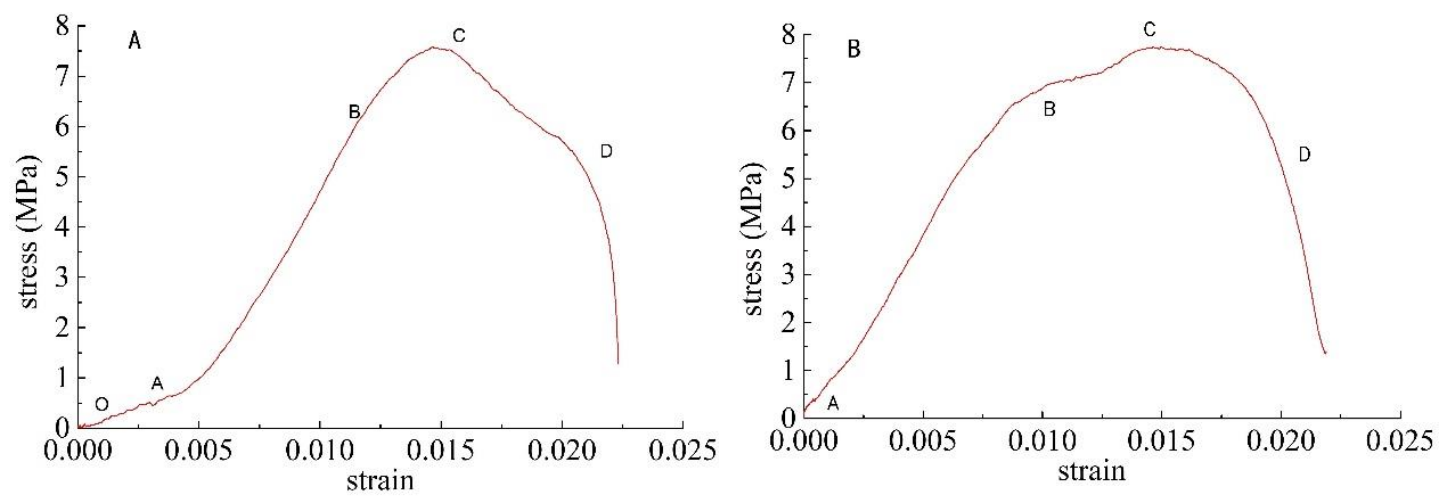

Fig 5. Deformation stages of backfill specimens (A, NO.75-4-90-4) and (B, NO.75-4-90-5) under SHPB uniaxial impact. Curve (A) includes micro-crack closure stage (section $\mathrm{OA}$ ), elastic deformation stage (section $\mathrm{AB}$ ), inelastic stage (section $\mathrm{BC}$ ), crack penetration and failure stage (section $\mathrm{CD}$ ). But there was almost no microcrack closure stage (section OA) of Curve (B).

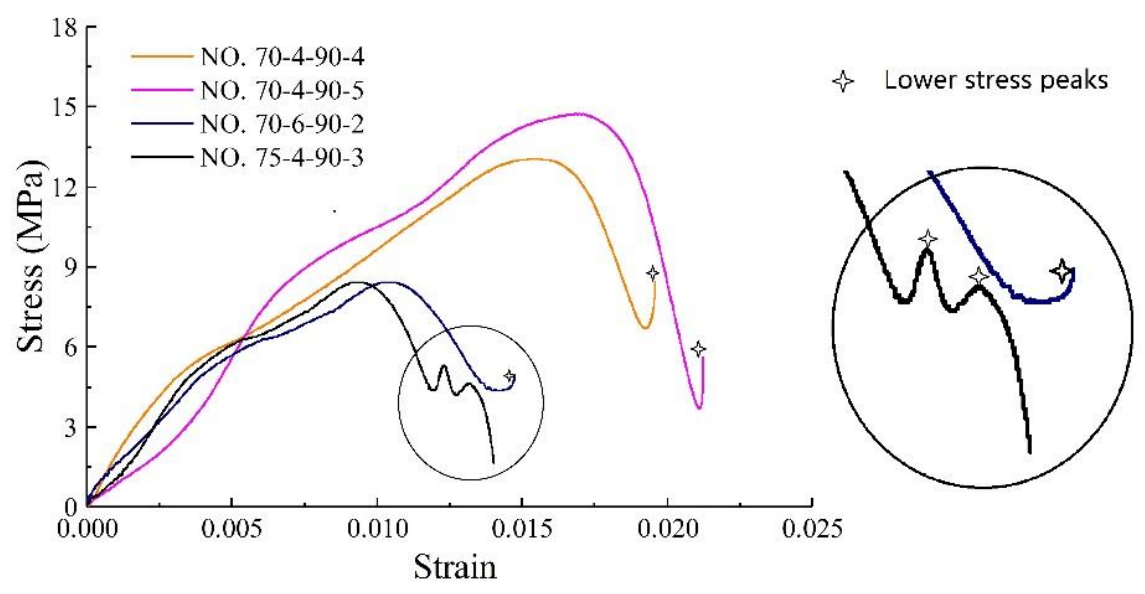

Fig 6. Stress-strain curves of some filling-body specimens dropped down to 1 2 lower stress peaks after the peak stress.

However, some CPB specimens didn't break totally but the stress wave of them dropped down to 1 2 lower stress peaks after the dynamic peak stress, as shown in Fig 6. That was very different 
from the stress-strain curves of general brittle rock under dynamic loading or CPB specimen under static load ${ }^{[41]}$, which don't rebound after the peak stress. In this situation, the stress began to decrease because only part of the CPB specimen were damaged after the peak stress. And then, the stress gradually increased to a second lower stress peak with the micro-cracks in the undamaged part began to be compressed and compacted. This phenomenon appeared 1 or 2 times until the CPB specimen was completely destroyed.

\subsection{Dynamic Strength Characteristic}

The experimental results of CPB specimen by SHPB uniaxial compression test are shown in table 2. In the table, the dynamic strength enhancement factor $\mathrm{K}$ is the increase of dynamic compressive strength relative to static compressive strength ${ }^{[42]}$. It can be calculated by the following formula:

$$
K=\frac{\sigma_{S}}{\sigma}
$$

Where $\sigma_{S}$ is the dynamic peak stress (dynamic compressive strength), and $\sigma$ is the static compressive strength.

Table 2. Experimental result by SHPB uniaxial compression test

\begin{tabular}{|c|c|c|c|c|c|c|c|}
\hline $\begin{array}{l}\text { Group } \\
\text { Number }\end{array}$ & Number & $\begin{array}{c}\text { Impact } \\
\text { Velocity } C / \mathrm{m} \cdot \mathrm{s}^{-}\end{array}$ & $\begin{array}{l}\text { Max Strain } \\
\text { Rate } \varepsilon_{S} / \mathrm{s}^{-1}\end{array}$ & $\begin{array}{c}\text { Average } \\
\text { Strain Rate } \\
\varepsilon / \mathrm{s}^{-1}\end{array}$ & $\begin{array}{c}\text { Dynamic } \\
\text { Peak } \\
\text { Stress } \sigma_{s} / \mathrm{MPa}\end{array}$ & $\begin{array}{c}\text { Dynamic } \\
\text { Strength } \\
\text { Enhancement } \\
\text { Factor } K\end{array}$ & $\begin{array}{c}\text { Static } \\
\text { Compressive } \\
\text { Strength } \\
\sigma / \mathrm{MPa}\end{array}$ \\
\hline \multirow{5}{*}{$70-4-90$} & 1 & 2.98 & 42 & 29 & 7.00 & 1.90 & \multirow{5}{*}{3.68} \\
\hline & 2 & 4.21 & 80 & 52 & 9.39 & 2.55 & \\
\hline & 3 & 4.41 & 84 & 57 & 10.58 & 2.88 & \\
\hline & 4 & 6.04 & 115 & 81 & 13.02 & 3.54 & \\
\hline & 5 & 6.88 & 128 & 91 & 14.74 & 4.01 & \\
\hline \multirow{5}{*}{$75-4-90$} & 1 & 2.81 & 40 & 26 & 6.52 & 1.19 & \multirow{5}{*}{5.48} \\
\hline & 2 & 3.06 & 58 & 39 & 7.17 & 1.31 & \\
\hline & 3 & 4.31 & 71 & 51 & 8.43 & 1.54 & \\
\hline & 4 & 6.10 & 128 & 84 & 13.88 & 2.53 & \\
\hline & 5 & 7.06 & 135 & 95 & 15.91 & 2.90 & \\
\hline \multirow{5}{*}{$70-6-90$} & 1 & 3.68 & 72 & 44 & 4.42 & 2.08 & \multirow{5}{*}{2.13} \\
\hline & 2 & 4.69 & 89 & 60 & 4.82 & 2.26 & \\
\hline & 3 & 5.10 & 101 & 69 & 5.35 & 2.51 & \\
\hline & 4 & 6.46 & 133 & 93 & 6.57 & 3.08 & \\
\hline & 5 & 6.73 & 135 & 97 & 7.47 & 3.51 & \\
\hline \multirow{5}{*}{$75-6-90$} & 1 & 2.39 & 30 & 20 & 4.35 & 1.16 & \multirow{5}{*}{3.74} \\
\hline & 2 & 4.74 & 90 & 60 & 7.87 & 2.10 & \\
\hline & 3 & 6.00 & 124 & 85 & 8.66 & 2.32 & \\
\hline & 4 & 6.32 & 130 & 90 & 8.89 & 2.38 & \\
\hline & 5 & 6.88 & 131 & 90 & 9.44 & 2.52 & \\
\hline \multirow{5}{*}{$70-8-90$} & 1 & 3.15 & 48 & 30 & 1.88 & 1.06 & \multirow{5}{*}{1.78} \\
\hline & 2 & 3.55 & 53 & 42 & 1.93 & 1.08 & \\
\hline & 3 & 4.46 & 80 & 60 & 2.46 & 1.38 & \\
\hline & 4 & 4.63 & 88 & 64 & 3.18 & 1.79 & \\
\hline & 5 & 5.60 & 115 & 80 & 4.24 & 2.38 & \\
\hline \multirow{5}{*}{$75-8-90$} & 1 & 3.21 & 52 & 39 & 3.29 & 1.26 & \multirow{5}{*}{2.61} \\
\hline & 2 & 4.55 & 115 & 79 & 5.04 & 1.93 & \\
\hline & 3 & 6.36 & 116 & 84 & 5.07 & 1.94 & \\
\hline & 4 & 6.56 & 115 & 86 & 5.23 & 2.00 & \\
\hline & 5 & 6.61 & 132 & 88 & 6.05 & 2.32 & \\
\hline
\end{tabular}

The comparison shows that:

(1) The strain rate of the CPB specimens gradually increased with the increase of impact velocity. And the variation range of it was larger than that of rock samples.

(2) The dynamic peak stress (dynamic compressive strength) of the CPB specimens increased with the increase of strain rate. For example, the average strain rate of the CPB specimen Group70-4- 
9 rose from 29 to 91 , result in the dynamic peak stress increased from 7.00 to 14.74. Regression analysis shows that the relationship between the dynamic peak stress $\sigma_{s}$ and average strain rate $\varepsilon$ is a quadratic equation, as shown in Fig 7. Moreover, the higher the cement-sand ratio was, the faster the dynamic stress peak increase with the average strain rate.

(3) When the average strain rate was between $30 \sim 40 s^{-1}$, the value of the dynamic peak stress of CPB specimens were close to the static compressive strength, and the dynamic strength enhancement factor $\mathrm{K}$ were nearly 1 . But the dynamic strength enhancement factor $\mathrm{K}$ increased with the rising of the strain rate. As a result, when the strain rate was between $80 \sim 100 \mathrm{~s}^{-1}$, the dynamic peak stress can be 2 3 times of the static compressive strength, or even 4.01 times of some CPB specimen (e.g., NO. 70-4-90-5). These was much higher than that of rock samples, the dynamic strength enhancement factor $\mathrm{K}$ of which is only between 1.20 to $2.50^{[40]}$.

(4) With a constant concentration, the greater the cement-sand ratio was, the higher K was; the greater the cement-sand ratio was, the faster variation rate of the dynamic peak stress change with the strain rate. This suggests that the variation efficiency of the strain increases with the increasing of cement- sand ratio.

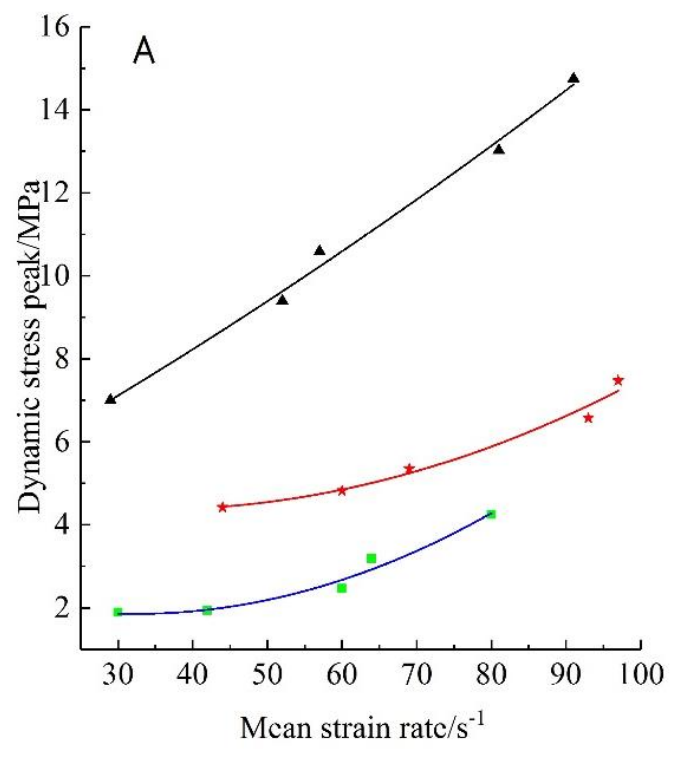

- Group 70-4-90

* Group 70-6-90

- Group 70-8-90

- Polynomial fitting

$\sigma_{p}=0.000226 \varepsilon^{2}+0.096 \varepsilon+4.048$

$\mathrm{R}^{2}=0.986$

_ Polynomial fitting

$\sigma_{p}=0.000731 \varepsilon^{2}-0.0504 \varepsilon+5.236$

$\mathrm{R}^{2}=0.949$

- Polynomial fitting

$\sigma_{p}=0.00106 \varepsilon^{2}-0.0689 \varepsilon+2.960$

$\mathrm{R}^{2}=0.943$

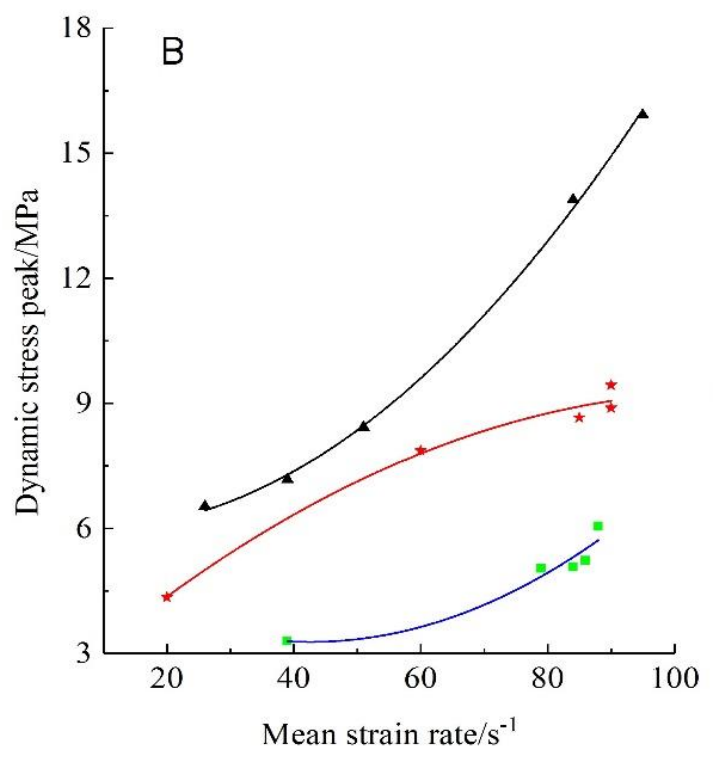

- Group 75-4-90

* Group 75-6-90

- Group 75-8-90

_ Polynomial fitting

$\sigma_{p}=0.00131 \varepsilon^{2}-0.0194 \varepsilon+6.050$

$\mathrm{R}^{2}=0.998$

— Polynomial fitting $\sigma_{p}=-0.000625 \varepsilon^{2}+0.1359 \varepsilon+1.894$

$\mathrm{R}^{2}=0.970$

Polynomial fitting

$\sigma_{p}=0.00118 \varepsilon^{2}-0.101 \varepsilon+5.431$

$\mathrm{R}^{2}=0.862$

Mean strain rate $/ \mathrm{s}^{-1}$ 
Fig 7. Relation curve of dynamic stress peak and average strain rate for (A) $70 \%$ concentration groups and (B) $75 \%$ concentration groups. All of them are quadratic equation relationship and the higher the cement-sand ratio was, the faster the dynamic stress peak increases with the mean strain rate.

\subsection{Dynamic Failure Characteristic}

At a high-speed compressive impact by SHPB, the CPB specimens were destroyed and broken instantaneously. Through a HD camera, we recorded the whole destruction and failure process, as shown in Fig.8(A-D), (E-H).
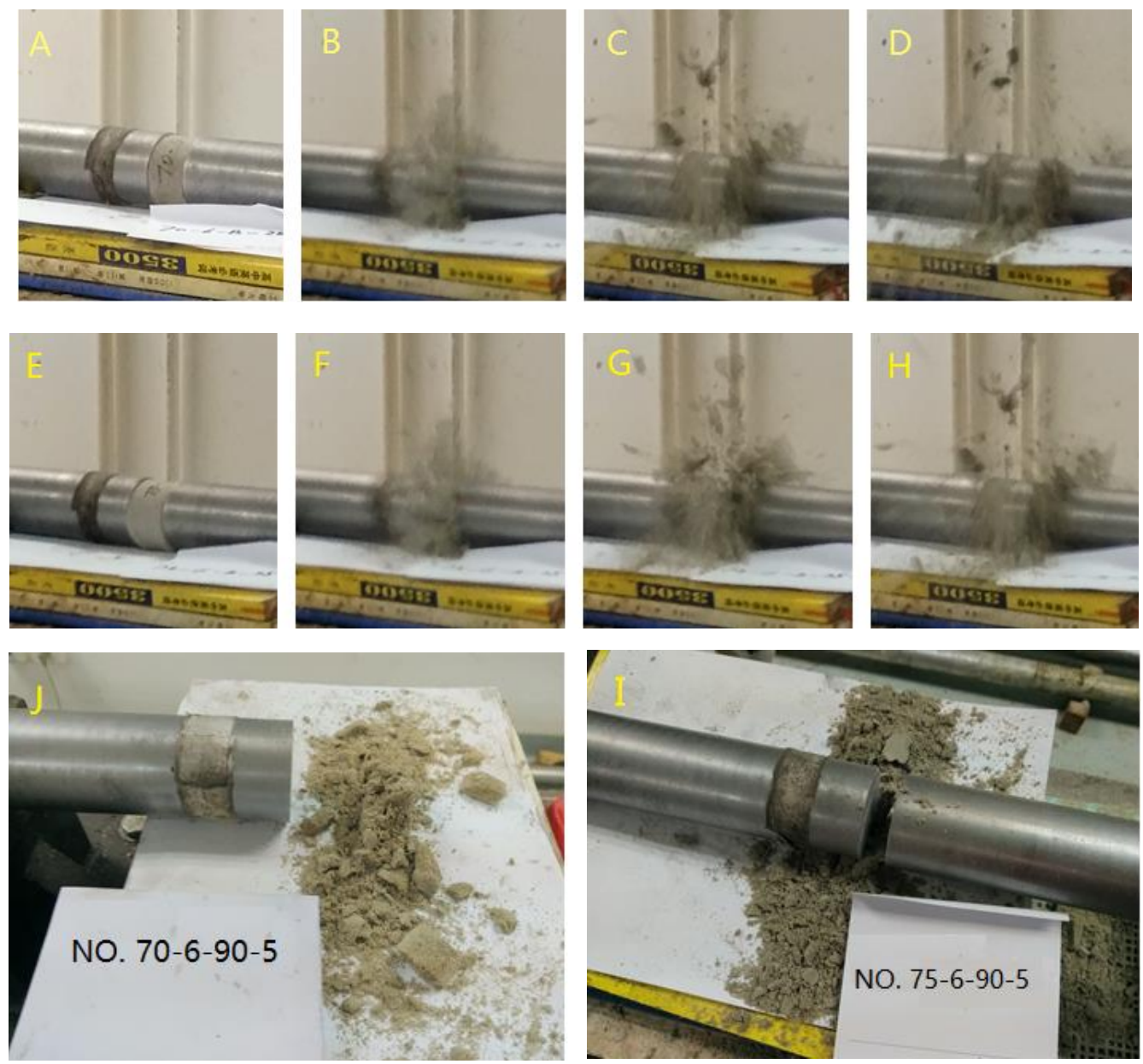

Fig 8. Failure process of the CPB specimens (A, B, C, D, failure process of NO.70-6-90-5) and (E, F, G, H, failure process of NO.75-6-90-5) under high-speed (6.37 $\mathrm{m} \cdot \mathrm{s}^{-1}$ on NO.70-6-90-5 and 6.88 $\mathrm{m} \cdot \mathrm{s}^{-1}$ on NO.75-6-90-5) impact of SHPB. They were completely broken and crushingly destroyed instantaneously, with scattered debris flying. Finally, they were broken into small pieces and crush power, as shown in (J, failure results of NO.70-6-90-5) and (I, failure results of NO.75-6-90-5).

The CPB specimens' failure mode under low velocity (around 4 5 $\mathrm{m} \cdot \mathrm{s}^{-1}$ ) impact were almost the same as that under uniaxial and triaxial static compression. There were three main types: shear failure, $\mathrm{X}$ conjugate shear failure and tensile failure (as shown in Fig.9) ${ }^{[43]}$. 

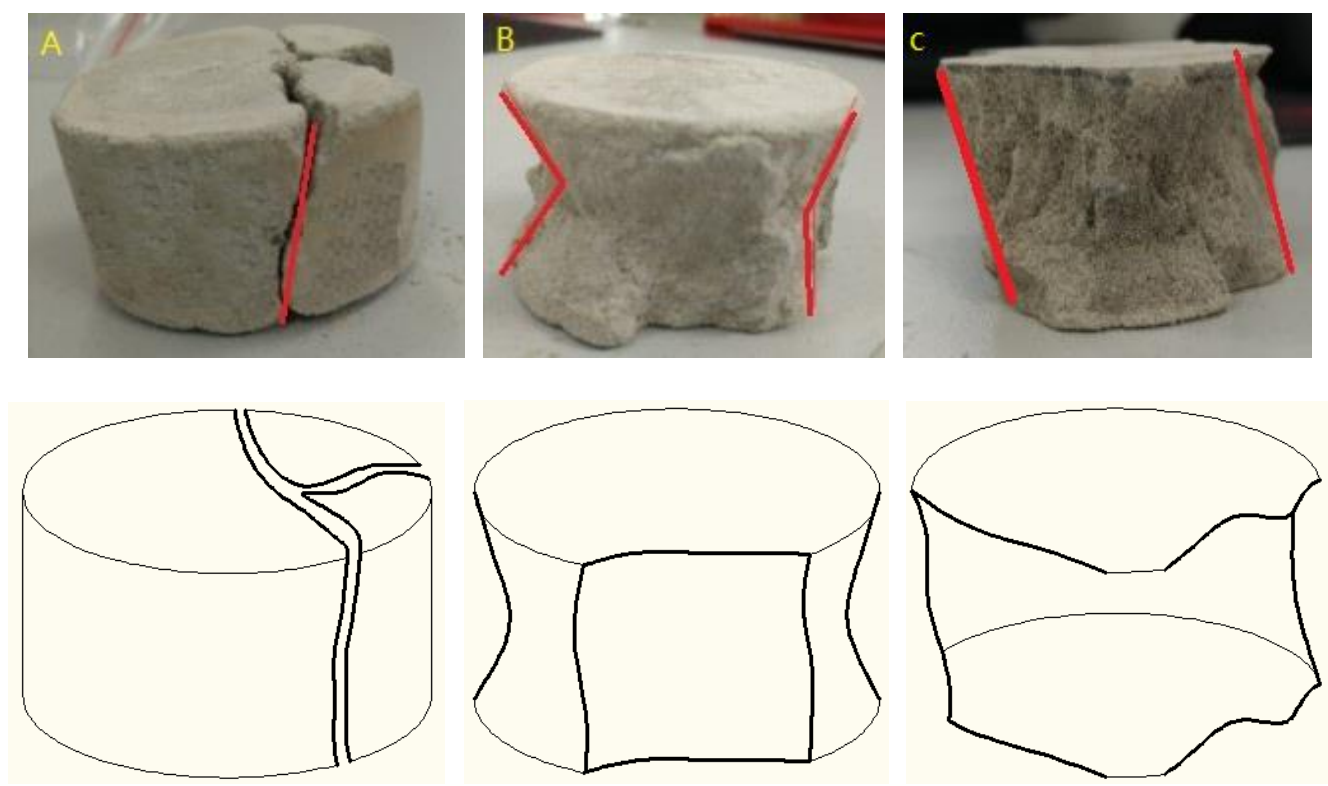

Fig 9. Failure modes of the CPB specimens under low velocity impact of SHPB. There were three main types: (A) shear failure, occurred in specimens NO.70-6-90-2 and NO. 75-4-90-2 under impact velocity $4.69 \mathrm{~m} \cdot \mathrm{s}^{-1}$ and $4.31 \mathrm{~m} \cdot \mathrm{s}^{-1}$; (B) X conjugate shear failure, occurred in specimens NO. 75-8-90-2 and NO. 75-6-90-2 under impact velocity $4.55 \mathrm{~m} \cdot \mathrm{s}^{-1}$ and $4.74 \mathrm{~m} \cdot \mathrm{s}^{-1}$; (C) tensile failure, occurred in specimens NO. 70-8-90-2 and NO. 70-4-90-3 under impact velocity $4.46 \mathrm{~m} \cdot \mathrm{s}^{-1}$ and $4.41 \mathrm{~m} \cdot \mathrm{s}^{-1}$

Failure forms and destroy degree of $\mathrm{CPB}$ specimens changed with the variation of impact velocity. For example, as shown in Fig 10, the failure forms and destroy degree of the 5 CPB specimens in Group 70-6-90 were much different. The higher the impact velocity and the strain rate were, the much crushing degree of the CPB specimen was. When the average strain rate was less than $50 \mathrm{~s}^{-1}$, only the sample's surrounding area was broken after being impacted, as shown in Fig 10 (A, B). When the strain rate increased to about $69 s^{-1}$, the CPB specimen broken to few parts along the main cracks, and there were micro-cracks appeared in both broken and unbroken areas, but the CPB specimen still had some residual strength, as shown in Fig 10 (C). When the strain rate increased to around $90 s^{-1}$, the crushing instability occurred, as shown in Fig 10 (D, E). That indicates the limit instability strain rate of this group's is about $90 \mathrm{~s}^{-1}$. At the limit strain rate, the CPB specimens performed crushing failure on the whole, similar to the failure form of low strength concrete samples. The CPB specimen cracked rapidly along the radial direction with ejection fragments under the dynamic impact by SHPB.
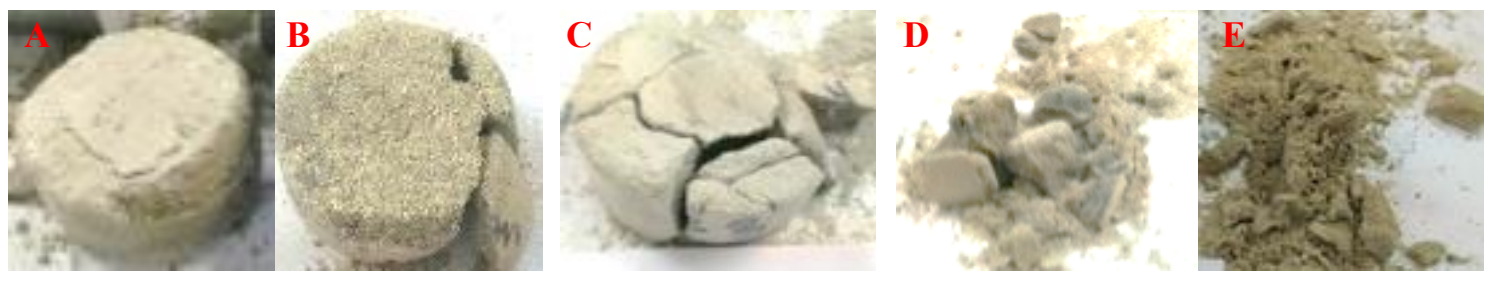

Fig 10. Failure forms and destroy degree of CPB specimens Group 70-6-90. (A) NO. 70-6-90-1, it almost had no destruction and kept as a whole and completeness under a low impact velocity $3.68 \mathrm{~m} \cdot \mathrm{s}^{-1}$; (B) NO. 70-6-90-2, still kept as a whole, but began to break from the peripheral and occurred a few fine cracks under an impact velocity $4.69 \mathrm{~m} \cdot \mathrm{s}^{-1}$; (C) NO. 70-6-90-3, be split to parts along main cracks which resulted in perforation failure under an impact velocity $5.10 \mathrm{~m} \cdot \mathrm{s}^{-1}$, but still kept little residual strength; (D) NO. 70-6-90-4, be crushed to many 
small parts and been completely instable. (E) NO. 70-6-90-5, be crushed to some small pieces and much crush power, was completely crushing destroyed.

\section{Conclusion}

(1) According to the experimental results under SHPB uniaxial compression test, the deformation and failure process of CPB specimens can be divided into following four stages: micro-crack closure stage, elastic deformation stage, inelastic stage, penetration and failure stage. Some CPB specimens did not broke immediately after the dynamic peak stress. The micro-cracks in unbroken areas of the CPB specimens been compressed and became closed. These resulted in 1 2 lower peak stress before they were totally broken.

(2) The dynamic peak stress (dynamic compressive strength) of the CPB specimens increased with the increase of impact velocity and was significantly affected by the ratio of cement-sand. The higher the ratio was, the greater the dynamic compressive strength was at similar impact velocity. The relationship between the dynamic compressive strength and the average strain rate is quadratic equation. Moreover, the higher the cement-sand ratio was, the faster the dynamic stress peak increase with the average strain rate. All these showed that the variation efficiency was more obvious when the cement-sand ratio of CPB specimens was higher. That means the variation efficiency of the strain increases with the increasing of cement- sand ratio.

(3) The dynamic peak stress (dynamic compressive strength) of the CPB specimens under low strain rate was close to that of static uniaxial compressive strength. With the increase of strain rate, the dynamic strength enhancement factor increases. It can be 2 3 times, or even up to 4.01 times of static uniaxial compressive strength when reached to the limit strain rate. These was higher than the dynamic strength enhancement factor of rock samples. When the concentration is constant, the higher the cement-sand ratio was, the greater the dynamic strength enhancement factor was.

(4) The failure forms of CPB specimens under low speed impact were almost the same as that under static uniaxial and axial compression, which are $\mathrm{X}$ conjugate shear failure, tensile failure and shear failure. But at the limit strain rate, the CPB specimens were basically crushed, which was similar to the failure form of low strength concrete samples.

Author Contributions: Y.T., and W.S. conceived and designed the experiments; L.X., X.Y., and Y.T. performed the experiments; L.X., X.Y., and Y.T. analyzed the data; Y.T., and X.Y. wrote the paper.

Acknowledgments: This work was supported by the National Key R\&D Program of China (2017YFC0602900), the Fundamental Research Funds for the Central Universities (FRF-TP-17-029A2).

Conflicts of Interest: The authors declare no conflict of interest.

\section{Reference}

1. He M.C.; Xie H.P.; Peng S.P., et al. Study on rock mechanics in deep mining engineering. Chinese Journal of Rock Mechanics and Engineering, 2005, 24(16), 2803-2813.

2. Hassanifp, Mortazavia, Shabanim. An investigation of mechanisms involved in backfill-rock mass behavior in narrow vein mining. Journal of the South African Institute of Mining and Metallurgy, 2008, 108(8), 463-472.

3. Rankiner, Pachecom, Sivakugann. Underground mining with backfills. Soils and Rocks, 2007, 30(2), 93-101.

4. Miao, X.X.; Zhang, J.X.; Guo, G.L. Waste Backfilling Method and Technology in Fully Mechanized Coal Mining. China University of Mining \& Technology Press, Xuzhou, China, 2010.

5. Benzaazoua, M.; Bussière, B.; Demers, I.; Aubertin, M.; Fried, É.; Blier, A. Integrated mine tailings 
management by combining environmental desulphurization and cemented paste backfill, Application to mine Doyon, Quebec, Canada. Miner. Eng. 2008, 21, 330-340.

6. Fall, M.; Pokharel, M. Coupled effects of sulphate and temperature on the strength development of cemented tailings backfills, Portland cement-paste backfill. Cem. Concr. Composit. 2010, 32, 819-828.

7. Sivakugan, N.; Rankine, R.M.; Rankine, K.J.; Rankine, K.S. Geotechnical considerations in mine backfilling in Australia. J. Clean. Prod. 2006, 14, 1168-1175.

8. Yang L. L.; Qiu J. P.; Jiang H. Q., et al. Use of cemented super-fine unclassified tailings backfill for control of subsidence, Minerals, 2017, 7, 216-236.

9. Doherty, J.P. A numerical study into factors affecting stress and pore pressure in free draining mine stopes. Comput. Geotech. 2015, 63, 331-341.

10. Ouellet, S.; Bussière, B.; Aubertin, M.; Benzaazoua, M. Microstructural evolution of cemented paste backfill, Mercury intrusion porosimetry test results. Cem. Concr. Res. 2007, 37, 1654-1665.

11. Yilmaz, E.; Belem, T.; Benzaazoua, M. Specimen size effect on strength behavior of cemented paste backfills subjected to different placement conditions. Eng. Geol. 2015, 185, 52-62.

12. Li, X.B.; Li, D.Y.; Liu, Z.X.; Zhao, G.Y.; Wang, W.H. Determination of the minimum thickness of crown pillar for safe exploitation of a subsea gold mine based on numerical modelling. Int. J. Rock Mech. Min. Sci. 2013, $57,42-56$.

13. Zhang, J.X.; Li, B.Y.; Zhou, N.; Zhang, Q. Application of solid backfilling to reduce hard-roof caving and longwall coal face burst potential. Int. J. Rock Mech. Min. Sci. 2016, 88, 197-205.

14. Deng, D.Q.; Liu, L.; Yao, Z.L.; Song, K.; Lao, D.Z. A practice of ultra-fine tailings disposal as filling material in a gold mine. J. Environ. Manag. 2017, 196, 100-109.

15. Ke, X.; Hou, H.; Zhou, M.;Wang, Y.; Zhou, X. Effect of particle gradation on properties of fresh and hardened cemented paste backfill. Constr. Build. Mater. 2015, 96, 378-382.

16. Khoshand, A.; Fall, M. Geotechnical characterization of peat-based landfill cover materials. J. Rock Mech. Geotech. Eng. 2016, 6, 1-9.

17. Li, M.; Zhang, J.X.; Zhou, N.; Huang, Y.L. Effect of Particle Size on the Energy Evolution of Crushed Waste Rock in Coal Mines. Rock Mech. Rock Eng. 2017, 50, 1-8.

18. Liang, C.; Fall, M. Mechanical and thermal properties of cemented tailings materials at early ages, Influence of initial temperature, curing stress and drainage conditions. Constr. Build. Mater. 2016, 125, 553-563.

19. Ercikdi, B.; Kesimal, A.; Cihangir, F. Cemented paste backfill of sulphide-rich tailings, Importance of binder type and dosage. Cem. Concr. Compos. 2009, 31, 268-274.

20. Liu C.; Han B.; Sun W., et al. Experimental study of strength of backfilling of cemented rock debris and its application under low temperature condition. Chinese Journal of Rock Mechanics and Engineering, 2015, 34(1), 139-147.

21. Tesarik D.R.; Seymour J.B.; Yanske T.R., Long-term stability of a backfilled room-and-pillar test section at the buick mine Missouri. International Journal of Rock Mechanics \& Mining Sciences, 2009, 46, 1182-1196.

22. Li, G.Y.; Fu, H.; Mi, Z.K. Test study on behaviors of grain crushing for rockfill materials. Rock Soil Mech. 2006, 27, 575-578.

23. Marsal, R.J. Mechanical properties of rockfill embankment dam engineering; John Wiley Sons Inc.: New York, NY, USA, 1973; pp. 109-200.

24. Fall, M.; Benzaazoua, M.; Ouellet, S. Experimental characterization of the influence of tailings fineness and density on the quality of cemented paste backfill. Miner. Eng. 2005, 18, 41-44. [

25. Kesimal, A.; Yilmaz, E.; Ercikdi, B.; Alp, I.; Yumlu, M.; Ozdemir, B. Laboratory testing of cemented paste backfill. Turk. Min. J. 2002, 41, 11-20.

26. Zhao, G.Y.; Wu, H.; Xu, Z.W.; Li, Z.Y.; Wang, E.J. Experimental study on load-bearing mechanism and 
compaction characteristics of mine filling materials. J. China Univ. Min. Technol. 2017, 6, 1251-1258, 1266.

27. Xu W.B.; Song W.D.; Wang D.X.; et al. Energy dissipation properties of cement backfill body under triaxle compression conditions. Journal of China University of Mining and Technology, 2014, 43(5), 808-814.

28. Xu W.B.; Cao P.W.; Tian M.M., Strength development and microstructure evolution of cemented tailings backfill containing different binder types and contents. Minerals, 2018, 8,167-182.

29. Yilmaz, E.; Kesimal, A.; Ercikdi, B. Evaluation of acid producing sulphidic mine tailings as a paste backfill. Turk. J. Earth Sci. Rev. 2004, 17, 11-19.

30. Yilmaz, E.; Belem, T.; Benzaazoua, M.; Kesimal, A.; Ercikdi, B. Evaluation of the strength properties of deslimed tailings paste backfill. Miner. Res. Eng. 2007, 12, 129-144.

31. Yilmaz, E. Investigating the Hydro-geotechnical and Microstructural Properties of Cemented Paste Backfills Using the Versatile CUAPS Apparatus. Ph.D. Thesis, Université du Québec en Abitibi-Témiscamingue UQAT, Rouyn-Noranda, QC, Canada, 2010; pp. 1-388.

32. Dong L.; Gao Q.; Nan S.Q.; et al. Performance and hydration mechanism of new super fine cemented wholetailings backfilling materials. Journal of Central South University (Natural Science), 2013, 44(4), 1571-1577.

33. Liu Z.X.; Li X.B.; Research on stability of high-level backfill in blasting. Mining and Metallurgical Engineering, 2004, 24(3), 22-24.

34. Zhou K.P.; Pan D., et al. Study on intensity response of rubble backfill to dynamic loading of medium-length hole blasting. Mining and Metallurgical Engineering, 2011, 31(4), 9-13.)

35. Zhang Q.L.; Yang W.; Yang S., et al. Test research on stability of high density total tailing cemented backfilling under dynamic loading. China Safety Science Journal, 2015, 25(3), 78-82.

36. Sun J.H.; Dou Y.M.; Zhou J., et al. Experimental study on the affect to compressive property of concrete caused by strain rate. China Concrete and Cement Products, 2011(05), 1-3.

37. Chen R.J.; Liu H.; Zeng R., SHPB dynamic experiment on silica fume concrete. Advanced Materials Research, 2013, 631(1), 771-775.

38. Fairhurst C.E.; Hudson J.A., Draft ISRM suggested method for the complete stress-strain curve for intact rock in uniaxial compression. International Journal of Rock Mechanics and Mining Sciences， 1999，36(3): 279-289.

39. Xu J.Y.; Fan J.S.; Lv X.C., et al. Dynamic mechanical properties of rock with the confining pressure. Xi'an, Northwestern Polytechnical University Press, 2012, 56-58.

40. Dai J., Dynamic behaviors and blasting theory of rock. Beijing, Metallurgical Industry Press, 2002, 60-90.

41. Fu J.X.; Du C.F.; Song W.D., Strength sensitivity and failure mechanism of full tailings cemented backfills. Journal of University of Science and Technology Beijing. 2014(9), 1149-1157.

42. Wang S.S.; Zhang M.H.; Quest S.T., Effect of sample size on static strength and dynamic increase factor of highstrength concrete from SHPB test. Journal of Testing and Evaluation, 2011, 39(5), 10-14.

43. Liu J.Z.; Xu J.Y.; Lu X., Experimental study on dynamic mechanical properties of amphibolies under impact compressive loading. Chinese Journal of Rock Mechanics and Engineering, 2009, 28(10), 2113-2120. 